\title{
Implementing Polarization-Corrected Temperature into Typhoon Rainfall Estimates over Taiwan from TRMM/TMI Data
}

\author{
Ming-Da Tsai ${ }^{1}$, Wann-Jin Chen ${ }^{2, *}$, and Jian-Liang Wang ${ }^{3}$ \\ ${ }^{I}$ School of Defense Science, Chung Cheng Institute of Technology, National Defense University, Taoyuan, Taiwan, ROC \\ ${ }^{2}$ Department of Electronic Engineering, Ta Hwa Institute of Technology, Hsinchu, Taiwan, ROC \\ ${ }^{3}$ Department of Environmental Information and Engineering, Chung Cheng Institute of Technology, \\ National Defense University, Taoyuan, Taiwan, ROC
}

Received 7 December 2008, accepted 15 June 2009

\begin{abstract}
The polarization-corrected temperature $(P C T)$ method is used to quantitatively estimate rainfall associated with typhoons over Taiwan. The satellite rainfall retrieval algorithms for TRMM/TMI (Tropical Rainfall Measuring Mission/TRMM Microwave Imager) have been developed according to rain types to improve the accuracy of the rainfall estimation. Measurements from precipitation radar (PR) are used to classify the rain types into three kinds including convective rain, stratiform rain with bright band and stratiform rain without bright band. Finally, rainfall retrievals are verified using PR near-surface rain rate (PR_RR), which is regarded as the "correct value."

Data from typhoons during 2001 to 2006 are used to set up the rain rate retrieval equations. First, cloud-free areas are identified using infrared satellite images as cases of no-scattering condition and the PCT equations are set up for Taiwan. Second, from the statistical analyses of the $P C T$ values with no-rain status, the rainfall threshold of $270 \mathrm{~K}$ is derived. Finally, the rain rate retrieval algorithms are set up using coincident $P C T$ values and PR_RR for different rain types.

Data from typhoons occurring from 2007 to 2008 are used for verification. The results show that the estimated values for convective and stratiform rain with bright band rain areas have better accuracy when the PCT method was used. For the stratiform rain without bright band, we find that the $P C T$ method is not suitable. Applying this approach to estimate the rain rates associated with Typhoon Haitang (2005), the $P C T$ method shows to have more reasonable rain rate estimation than the SIL (scattering index on land) method, with or without rain type classification. In addition, using $85 \mathrm{GHz}$ data only, the $P C T$ method shows higher rain rate retrieval resolution than the SIL method. Overall, we recommend that the PCT method can be used for quantitative precipitation estimation.
\end{abstract}

Key words: Quantitative rain rate estimation, Polarization-corrected temperature method, Scattering index on land method, Rain type, Rain threshold

Citation: Tsai, M. D., W. J. Chen, and J. L. Wang, 2010: Implementing polarization-corrected temperature into typhoon rainfall estimates over Taiwan from TRMM/TMI data. Terr. Atmos. Ocean. Sci., 21, 697-712, doi: 10.3319/TAO.2009.06.15.01(A)

\section{INTRODUCTION}

Taiwan is a mountainous island with many high mountains up to about $4000 \mathrm{~m}$ elevation. During the past several decades, due to over-development on mountain slopes, conservation of soil and water has been a challenging effort for natural resources managers. Copious rainfall brought by typhoons often cause debris flows in upstream areas of mountain ranges, serious flooding, and loss of land. This leads to enormous economic losses and damage in Taiwan. And yet,

\footnotetext{
* Corresponding author

E-mail:wannjin@gmail.com
}

rainfall brought by typhoons is the primary source of fresh water in Taiwan. Therefore, improving the forecasting techniques and providing early warnings for heavy rainfall to effectively reduce the loss caused by disasters is an important goal for meteorologists in Taiwan.

With the rapid development of satellite technology in recent years, satellite microwave data have become a major observational source for rainfall research on an international basis. This is because microwaves penetrate through clouds and directly observe hydrometeors within precipitating clouds. Because Taiwan is surrounded by oceans, it is 
convenient to use meteorological satellites to monitor and track weather systems with heavy rainfalls and acquire the information needed for flood mitigation. In the past few years, several researchers in Taiwan conducted studies on rainfall retrievals with passive microwave data over oceans and their results indicated that the rainfall retrieval technique performed well (Chen and Li 2000, 2002; Hu 2002; Chen 2004).

Chen and Tsai (2005) used the scattering index method to develop the satellite rainfall retrieval method in Taiwan. To verify rain gauge observations, Ferraro and Marks (1995) used the land rainfall retrieval algorithm (LRCT) and the results derived from LRCT were better than those derived from LRFM.

Because the land emissivity is more complicated than that over the ocean, it is difficult to estimate rainfall using the absorption method on land. Therefore, the research on land rainfall retrieval is mainly focused on the scattering method (Grody 1991; Wilheit et al. 2003), through which the rainfall estimation formula was easily established. In the radiative transfer process, radiation energy is scattered out of the line-of-sight by ice content above freezing layer and by large raindrops below the freezing layer, thus reducing the brightness temperature $(T B)$. Thus, with the decrease of temperature, more ice content and larger raindrops, stronger scattering occurs and leads to more rainfall on land. In other words, the scattering method is used to estimate the land rainfall indirectly based on the concept that the decrease of $T B$ is mainly caused by ice content and large raindrops. Meanwhile, the reduction of $T B$ at high frequency is much more than that at low frequency, especially when strong convection increases the thickness of ice content above the freezing layer.

When the scattering method is applied to the rainfall retrieval on land, the influence of scattering materials, such as snow, sea ice and desert land cover, should be separated (Ferraro et al. 1996; Weng et al. 1997). However, there is no desert terrain in Taiwan and no snow-covered areas during the typhoon season. Therefore, in this study, there is no need to consider these sources of scatter. On the other hand, since Taiwan is surrounded by oceans, it is necessary to remove samples including coastal areas to avoid the influence of the ocean's cold background emission.

Using the distinct features between the horizontally and vertically polarized $T B$ s, Spencer (1986) identified norain areas over the ocean under high polarization difference and rainy areas with little polarization difference. The $P C T$ (polarization-corrected temperature) parameter is defined as:

$P C T=\left(\beta T B_{h}-T B_{v}\right) /(\beta-1)$

where $T B_{h}$ and $T B_{v}$ are, respectively, the observed values of horizontally and vertically polarized $T B \mathrm{~s}$ and $\beta$ is defined as the follows:

$\beta=\left(T B_{v c}-T B_{v o}\right) /\left(T B_{h c}-T B_{h o}\right)$

where $T B_{v c}, T B_{v o}, T B_{h c}, T B_{h o}$ are the observed value of vertically polarized and horizontally polarized $T B$ s under a cloud-free and atmospheric-free states, respectively.

According to Spencer et al. (1989), the PCT value can be obtained if $\beta=0.45$ is substituted into the Eq. (1), and the Eq. (3) for $P C T$ is then derived. The threshold of precipitation is $255 \mathrm{~K}$.

$P C T=1.818 T B_{v}-0.818 T B_{h}$

The main advantage of the $P C T$ method is its ability to reduce the effect of background surface emissivities, making it possible to delineate areas of rainfall over varying surface types (Kidd 1998). Therefore it is very useful for developing the rain rate algorithm on land with complicated surface emissivities. Todd and Bailey (1995) applied the $P C T$ method to estimate rainfall in Britain and the nearby seas, and validated them with land-based radar network and rain gauges. The relationship between land rainfall $R R$ and $P C T$, established by an empirical method, was $\log (R R)=a+b(P C T-T i)$, where $T i$ was the rainfall threshold of PCT; $a$ and $b$ were constants to be determined. Because the coefficients of this formula were dependent on the data used, they may not be suitable for Taiwan. In this study, the PCT method is adopted to quantitatively estimate typhoon rainfall in Taiwan, but with new coefficients determined from data for Taiwan.

Convective clouds can be classified on a convective scale, whose spatial range is from 1 to $10 \mathrm{~km}$ (e.g., see Fujita 1986; Holton 2004). Tsai et al. (2008) developed the land rainfall retrieval with the SIL (scattering index on land) method using 3 different TRMM/TMI (Tropical Rainfall Measuring Mission/TRMM Microwave Imager) channels $(19.35,37.0,85.5 \mathrm{GHz})$ with $10-\mathrm{km}$ spatial resolution. The scattering index (SI) method at $85 \mathrm{GHz}$ with SSM/I instruments was initiated by Grody (1991). The key idea is that the signal from land surface emitted radiation is affected by ice particles and large raindrops much more at high-frequency (e.g., $85.5 \mathrm{GHz}$ ) than at low-frequency (e.g., $19.35 \mathrm{GHz}$ ). The $85-\mathrm{GHz} T B$ in clear-sky state (i.e., non-scattering condition) was simulated by $19-\mathrm{GHz}$ vertical polarization $T B\left(T B_{19 v}\right), 21-\mathrm{GHz}$ vertical polarization $T B\left(T B_{21 v}\right)$, and the quadratic term of $T B_{21 v}$. The difference between the simulated clear-sky $85-\mathrm{GHz} T B$ and the actual measured $85-\mathrm{GHz} T B$ is a measure of the degree of scattering by ice particles and large raindrops and the rain rate is proportional to the amount of scattering. The SI greater than $10 \mathrm{~K}$ was suggested as a rainfall threshold by Grody (1991) on a global scale. Because the 10-km spatial resolution is inadequate to analyze the convective cell, this study 
uses $85.5-\mathrm{GHz}$ channel observations with $5-\mathrm{km}$ resolution to improve the accuracy of the satellite retrieval rain rates, especially for the convective cells for Taiwan.

Prabhakara et al. (2002) collected TMI and PR data from 20 cases of MCS on land. Whereas the rain rate varied greatly varies from 5.9 to $20.1 \mathrm{~mm} \mathrm{~h}^{-1}$, the differences among $T B \mathrm{~s}\left(T B_{85}, T B_{37}\right.$ and $\left.T B_{19}\right)$ were, however, quite small (less than $3 \mathrm{~K}$ ). This is because different rain types, either convective or stratiform, may have different rain rates even though they have the same TB. Tsai et al. (2008) studied the land rainfall retrieval using the SIL method in combination with TRMM/PR (precipitation radar) rain type data to classify the rainfall areas for Taiwan. The satellite rainfall estimation accuracy showed significant improvement, especially in the bright-band stratiform rainfall areas.

In order to have a sample size large enough for the derivation of rainfall retrieval algorithms using the statistical method, the PR near-surface rain rates (PR_RR) are used as the "ground truth." According to Demoss and Bowman (2007), the PR estimated rain rates have low bias compared with rain gauge observations. Tsai et al. (2006) utilized rain gauge data to verify the PR_RR and showed that the rain maps derived from PR_RR and rain gauges were compatible for typhoon cases and the average correlation coefficient is 0.54 .

This study mainly uses the $P C T$ method with the help of standard products of TRMM/PR (2A25) to obtain rainfall retrieval algorithms for different rain types (Iguchi et al. 2000) to improve the accuracy of land rainfall retrieval in Taiwan. In section 2 of this paper, the characteristics of TRMM/TMI 85-GHz TBs for the typhoon precipitation in Taiwan are described. Data collection and processing are described in section 3 . In section 4 , rainfall retrieval using the PCT method for land rainfall in Taiwan is described, including the establishment the $P C T$ equation, the precipitation threshold. Using PR_RR as the ground truth, the validation of rainfall retrieval results for Taiwan is described in section 5 and some conclusions in section 6 are presented.

\section{CHARACTERISTICS OF TRMM/TMI 85-GHZ TBS FOR THE TYPHOON PRECIPITATION IN TAIWAN}

Here we discuss the characteristics of $T B_{85 v}$ and $T B_{85 h}$ during Typhoon Toraji on 29 July 2001. The PR_RR and rain-type data are used to derive the relationship between TMI 85-GHz dual-polarized TBs and rain rates under different rain types. Figure 1a shows the surface precipitation distribution estimated by PR. At that time, there were two centers of heavy precipitation. This is consistent with the 24-h accumulated rainfall recorded by the rain gauge network of the Central Weather Bureau of Taiwan as shown by Yang and Ching (2005). The circles in the diagram represent the footprints of the TMI pixels and the resolution of each FOV (field of view) is $10 \mathrm{~km}$. The TMI data along the curve A - B, 25 FOVs in total, passing through the heavy precipitation center in southern Taiwan are chosen for analysis. Figure $1 \mathrm{~b}$ shows the vertical cross-section of the precipitation along the A - B curve. At Point A over ocean, there is no rain. Approaching the coast, the rain type is stratiform
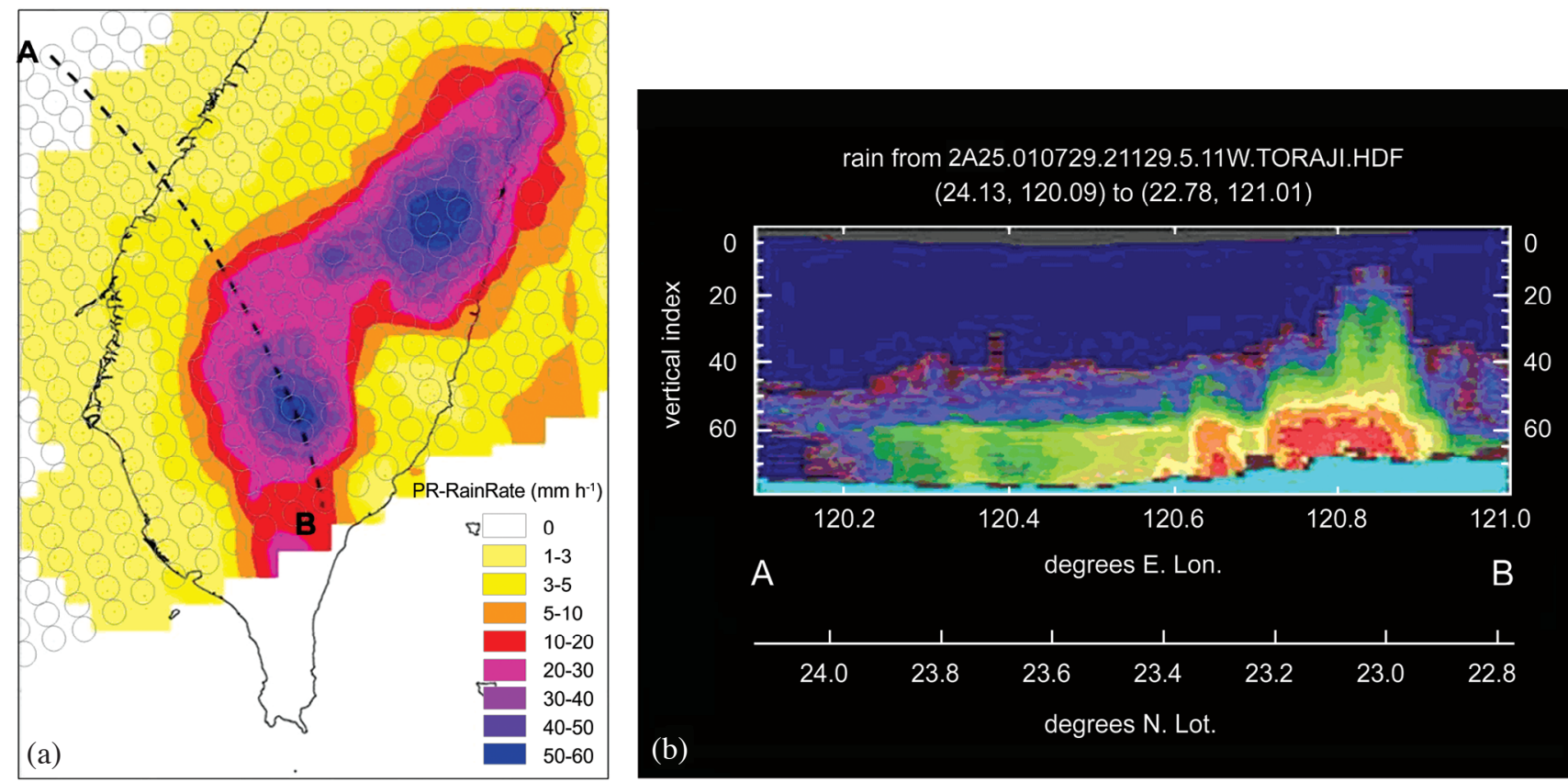

Fig. 1. (a) The distribution of the rain rate $\left(\mathrm{mm} \mathrm{h}^{-1}\right)$ derived by PR for Typhoon Toraji on 29 July 2001. Circles represent the footprints of the TMI pixels and the resolution of each FOV (field of view) is $10 \mathrm{~km}$. (b) The vertical cross-section of the precipitation along the curve A - B shown on panel (a). The vertical index is the layer number. The altitude of layer 60 , for example, is about $(80-60) \times 0.25 \mathrm{~km}=5.0 \mathrm{~km}$. 
and the rainfall intensity is light. It is then followed by heavy rainfall over the mountainous area. The echo height of the stratiform rain is about $6 \mathrm{~km}$ and the bright bands exist at the height of $5 \mathrm{~km}$. On the other hand, the rain type is convective with tops extending to the height over $15 \mathrm{~km}$ nearby Point B.

In Fig. 2, $T B_{85}, T B_{85 h}$, their differences, PR_RR, and rain types are shown to analyze the relationship between $T B_{85 v}, T B_{85 h}$, and surface precipitation along the A - B track, shown in Fig. 1. In the figure, both $T B_{85 v}$ and $T B_{85 h}$ decrease with increasing surface rain rate, and the difference between $T B_{85 v}$ and $T B_{85 h}$ is relatively smaller in the convective rain area. Particularly, in the data for convective rain, the difference is almost zero. On the other hand, the difference between $T B_{85 v}$ and $T B_{85 h}$ is larger in the land and ocean areas with no precipitation as well as areas with stratiform precipitation. In areas with no rain, both $T B_{85 v}$ and $T B_{85 h}$ are over $250 \mathrm{~K}$ and their difference ranges from 13 to $18 \mathrm{~K}$. In the stratiform rain areas, both $T B_{85 v}$ and $T B_{85 h}$ decrease with the increase of surface rain rate. When there is surface precipitation, both $T B_{85 v}$ and $T B_{85 h}$ are below $230 \mathrm{~K}$, and their difference is from 12 to $19 \mathrm{~K}$. In areas with convective rain, both $T B_{85 \mathrm{v}}$ and $T B_{85 \mathrm{~h}}$ are below $190 \mathrm{~K}$ where the rain rate is above $25 \mathrm{~mm} \mathrm{~h}^{-1}$, and their difference is less than $1 \mathrm{~K}$.

Through the above analysis, it can be shown that the observed TBs in the TMI high-frequency channels are mainly determined by the rain rate and are less affected by the background emission, as expected theoretically for the scattering channels. The larger the surface rain rate, the more scattering hydrometeors in the atmosphere, and, hence, smaller $T B$ values are observed. The observed $T B$ value at the convective cell is the lowest in the precipitation system. In addition, as for difference of polarization, in the no-rain and stratiform rain areas, the difference between $T B_{85 v}$ and $T B_{85 h}$, on average, is larger than in the convective area. Using SSM/I data Spencer et al. (1989) found that, in stratiform rain areas on land, the difference between horizontal and vertical polarizations at the $85.5-\mathrm{GHz}$ channel could be over $5 \mathrm{~K}$, while the two are almost equal in convective rain areas. Various studies have shown that the main contribution for observation of polarization is related not only to the orientation of polarized ice particles, but also to the total amount of asymmetric snow and ball-shaped hail particles in convective and stratiform rain areas (Roberti and Kummerow 1999). In stratiform rain areas, there is a higher content of asymmetric snowflakes with directional polarized factors, and the difference of polarization at $85 \mathrm{GHz}$ could be over $10 \mathrm{~K}$. In convective rain areas, there is a higher content of ball-shaped hail particles, which may cause the difference of polarization to be lower than $5 \mathrm{~K}$ (William et al. 2001). Therefore, the difference of polarization values can also be the basis for assigning convective or stratiform rain types.

\section{DATA SOURCES AND PROCESSING}

The scope of this study covers land areas of Taiwan. Satellite data used in this study include TMI (1B11), Visible/Infrared Scanner (VIRS, 1B01) and PR (2A25) data from TRMM Orbital Data Products (Kummerow et al. 1998) (http://disc.sci.gsfc.nasa.gov/data/datapool/TRMM/index. $\underline{\mathrm{html}}$ ) for 37 typhoons during 2001 to 2008 , as shown in Table 1. Typhoons occurring during 2001 to 2006 are used to develop the rainfall retrieval algorithm, and typhoons from 2007 to 2008 are used for verification. The rainfall retrieval algorithm is then further applied to the estimation of the rainfall rates associated with Typhoon Haitang (2005).

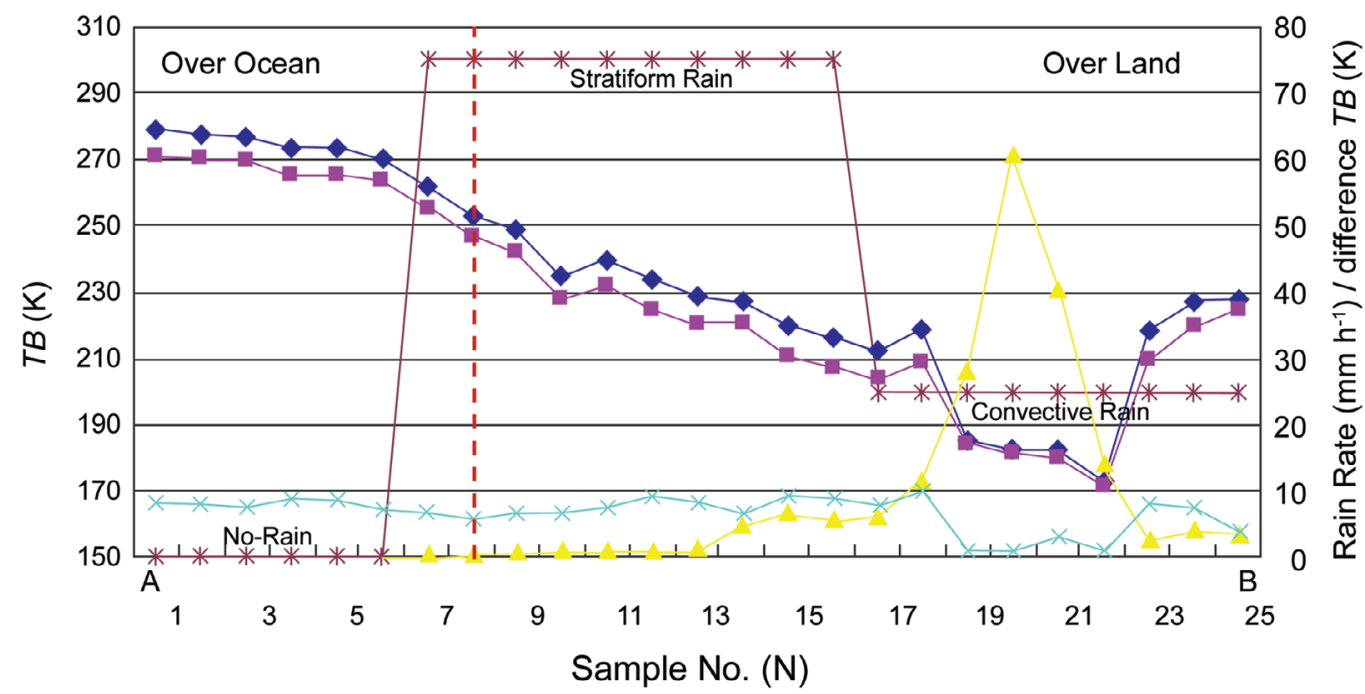

Fig. 2. Observed microwave $T B$ s and PR_RR of the 25 sample points along the A - B track, shown in Fig. 1. The blue, red, and light blue lines represent $T B_{85 v}, T B_{85 h}$, and the difference between $T B_{85 v}$ and $T B_{85 h}$, respectively; the yellow line represents PR_RR (mm $\left.\mathrm{h}^{-1}\right)$ and the purple line represents rain types. 
Table 1 . The 37 typhoons that were observed by the TRMM satellite when they made landfall on Taiwan from $2001 \sim 2008$.

Typhoons from 2001 to 2006 are used to set up the rainfall retrieval equations.

\begin{tabular}{|c|c|c|c|c|c|c|c|c|c|c|c|}
\hline No. & Date & Orbit & Typhoon & No. & Date & Orbit & Typhoon & No. & Date & Orbit & Typhoon \\
\hline 1 & $2001 / 05 / 11$ & 19883 & \multirow{2}{*}{ Cimaron } & 17 & $2002 / 07 / 03$ & 26413 & \multirow{2}{*}{ Rammasun } & 33 & $2005 / 07 / 19$ & 43738 & Haitang \\
\hline 2 & $2001 / 05 / 12$ & 19894 & & 18 & $2002 / 07 / 03$ & 26417 & & 34 & $2005 / 08 / 03$ & 43982 & \multirow{2}{*}{ Matsa } \\
\hline 3 & $2001 / 06 / 23$ & 20558 & Chebi & 19 & $2003 / 06 / 01$ & 31607 & Nangka & 35 & $2005 / 08 / 04$ & 43986 & \\
\hline 4 & $2001 / 07 / 04$ & 20732 & \multirow{2}{*}{ Utor } & 20 & $2003 / 06 / 17$ & 31851 & Soudelor & 36 & $2005 / 09 / 10$ & 44566 & Khanun \\
\hline 5 & $2001 / 07 / 05$ & 20743 & & 21 & $2003 / 08 / 04$ & 32595 & Morakot & 37 & $2005 / 09 / 21$ & 44734 & \multirow{2}{*}{ Damrey } \\
\hline 6 & $2001 / 07 / 11$ & 20840 & Trami & 22 & $2003 / 11 / 02$ & 33999 & Melor & 38 & $2005 / 09 / 21$ & 44745 & \\
\hline 7 & $2001 / 07 / 30$ & 21133 & Toraji & 23 & $2004 / 07 / 01$ & 37777 & \multirow{3}{*}{ Mindulle } & 39 & $2005 / 10 / 01$ & 44898 & \multirow{2}{*}{ Longwang } \\
\hline 8 & $2001 / 09 / 06$ & 21731 & \multirow{5}{*}{ Nari } & 24 & $2004 / 07 / 02$ & 37785 & & 40 & $2005 / 10 / 01$ & 44902 & \\
\hline 9 & $2001 / 09 / 16$ & 21895 & & 25 & $2004 / 07 / 03$ & 37800 & & 41 & $2006 / 07 / 25$ & 49527 & Kaemi \\
\hline 10 & $2001 / 09 / 17$ & 21899 & & 26 & $2004 / 07 / 14$ & 37972 & Kompasu & 42 & $2006 / 08 / 09$ & 49756 & Bopha \\
\hline 11 & $2001 / 09 / 17$ & 21910 & & 27 & $2004 / 07 / 14$ & 37983 & & 43 & $2006 / 08 / 10$ & 49767 & \multirow{2}{*}{ Saomai } \\
\hline 12 & $2001 / 09 / 17$ & 21914 & & 28 & $2004 / 08 / 12$ & 38426 & Rananim & 44 & $2006 / 08 / 10$ & 49771 & \\
\hline 13 & $2001 / 09 / 24$ & 22017 & \multirow{4}{*}{ Lekima } & 29 & $2004 / 08 / 24$ & 38609 & \multirow{2}{*}{ Aere } & 45 & $2006 / 09 / 15$ & 50336 & \multirow{3}{*}{ Shanshan } \\
\hline 14 & $2001 / 09 / 27$ & 22067 & & 30 & $2004 / 08 / 24$ & 38613 & & 46 & $2006 / 09 / 16$ & 50347 & \\
\hline 15 & $2001 / 09 / 28$ & 22078 & & 31 & $2004 / 09 / 26$ & 39128 & \multirow{2}{*}{ Meari } & 47 & $2006 / 09 / 16$ & 50351 & \\
\hline 16 & $2001 / 09 / 28$ & 22082 & & 32 & $2004 / 09 / 26$ & 39132 & & \multicolumn{3}{|c|}{ Total Typhoons } & 26 \\
\hline
\end{tabular}

Typhoons from 2007 to 2008 are used for verification.

\begin{tabular}{|c|c|c|c|c|c|c|c|c|c|c|c|}
\hline No. & Date & Orbit & Typhoon & No. & Date & Orbit & Typhoon & No. & Date & Orbit & Typhoon \\
\hline 1 & 2007/08/08 & 55434 & WUTIP & 7 & $2007 / 10 / 07$ & 56365 & KROSA & 13 & $2008 / 09 / 12$ & 61677 & \\
\hline 2 & 2007/09/17 & 56060 & \multirow{3}{*}{ WIPHA } & 8 & $2008 / 07 / 18$ & 60803 & KALMAEGI & 14 & 2008/09/12 & 61688 & SINLAKU \\
\hline 3 & 2007/09/18 & 56071 & & 9 & $2008 / 07 / 28$ & 60971 & FUNG-WONG & 15 & 2008/09/13 & 61692 & \\
\hline 4 & 2007/09/18 & 56075 & & 10 & $2008 / 08 / 20$ & 61326 & \multirow{2}{*}{ NURI } & 16 & $2008 / 09 / 22$ & 61845 & HAGUPIT \\
\hline 5 & 2007/10/06 & 56350 & \multirow{2}{*}{ KROSA } & 11 & $2008 / 08 / 21$ & 61337 & & 17 & $2008 / 09 / 27$ & 61917 & JANGMI \\
\hline 6 & 2007/10/07 & 56361 & & 12 & 2008/09/11 & 61673 & SINLAKU & \multicolumn{3}{|c|}{ Total Typhoons } & 10 \\
\hline
\end{tabular}

Typhoon used to apply the derived rainfall retrieval equations.

\begin{tabular}{c|c|c|c|c|c|c|c|c|c}
\hline No. & Date & Orbit & Typhoon & No. & Date & Orbit & Typhoon & No. \\
\hline 18 & $2005 / 07 / 19$ & $\begin{array}{c}43742 \\
\text { swath 1 }\end{array}$ & Haitang & 19 & $2005 / 07 / 20$ & $\begin{array}{c}43753 \\
\text { swath } 2\end{array}$ & Haitang & Total Typhoons \\
\hline
\end{tabular}


Before establishing the relationship between microwave $T B \mathrm{~s}$ and rainfall rates, the matched satellite microwave data and PR_RR must be collected. In order to have homogeneous microwave pixel data, high-resolution $(2.2 \mathrm{~km})$ data from VIRS Level 1B01 co-locating with TMI data are used to remove samples with beam-filling error.

\section{RAINFALL RETRIEVAL USING PCT METHOD IN TAIWAN}

In this section, data from 26 typhoons which made landfall in Taiwan from 2001 to 2006 are used for Taiwan land rainfall retrieval using the $P C T$ method.

\subsection{Establishment of the PCT Equation for Taiwan Region}

Before a typhoon affects Taiwan, its peripheral areas are usually dominated by subsidence. During these periods, Taiwan usually experiences a cloud-free weather and there is no scattering matter (ice content) in the atmosphere. In Fig. 3, five zones are marked out in the ocean areas adjacent to Taiwan for sampling cloud-free data. VIRS data are used to select the atmosphere samples without scattering hydrometeors for establishing the PCT equation for Taiwan region. There are 4121 samples in total for the 7 typhoons prior to making landfall in Taiwan in 2001. Figure 4 shows the scatter diagram of TRMM/TMI $T B_{85 v}$ and $T B_{85 h}$ data and the dashed line is the linear regression line. Figure 4 shows that, at times when it is cloud free over the sea, the $T B$ s of vertical polarization are all higher than those of horizontal polarization, with differences of about 5 to $37 \mathrm{~K}$. The linear regression equation for these samples can be determined by the distribution of the data and is as follows.

$T B_{85 h}=2.171\left(T B_{85 v}\right)-339.84$

From Eq. (4), the slope of the regression line is $m=$ 2.171 , and $\beta=1 / \mathrm{m}=0.461$ is then derived. Note that $\beta=$ 0.45 was derived and assumed to be a constant by Spencer (1989). Barrett and Kidd (1990) considered that $\beta$ must vary with locations and seasons, and suggested $\beta=0.39$ for application to northwestern Europe during summer to autumn. The derived $\beta$ in this study is recommended for application to Taiwan during the typhoon season.

Substituting the derived $\beta$ into Eq. (1), the PCT equation for Taiwan region can then be obtained.

$P C T=1.855\left(T B_{85 v}\right)-0.855\left(T B_{85 h}\right)$

In Fig. 4, as the dashed line is extended, and intersects with the line of $T B_{85 v}=T B_{85 h}$ at $290.3 \mathrm{~K}$. This point is the $P C T$ of the background under cloud-free conditions.

\subsection{Rainfall Threshold for Taiwan Land Area}

To define the rainfall threshold of the $P C T$ for Taiwan, the $P C T$ values were obtained based on Eq. (5), and then matched with PR_RR. After being filtered, 5864 points were obtained for typhoons making landfall in Taiwan in 2001 with rain rates of $0 \mathrm{~mm} \mathrm{~h}^{-1}$ on land. Their distribution is shown in Fig. 5. The mean value of $P C T$ is $282.31 \mathrm{~K}$ and the standard deviation is $6.17 \mathrm{~K}$. The confidence intervals (95\% level) are then $269.97 \mathrm{~K}<P C T<294.65 \mathrm{~K}$ for the rainfall threshold. Here, the lower end of the interval, $270 \mathrm{~K}$, is taken as the rainfall threshold (Ti) for Taiwan. That is, it is assumed to have none-zero rain rate wherever the $P C T$ is less than $270 \mathrm{~K}$.

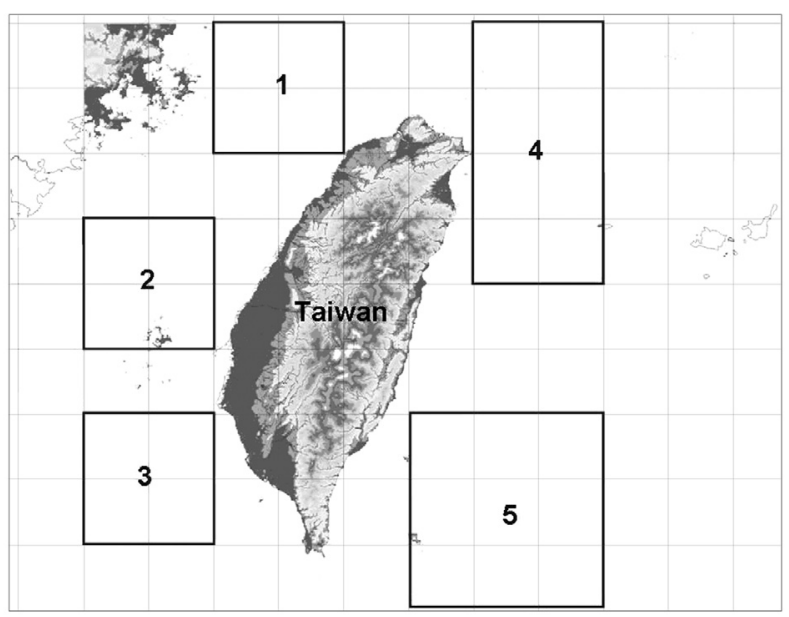

Fig. 3. The five areas over ocean are marked out for sampling cloudfree data.

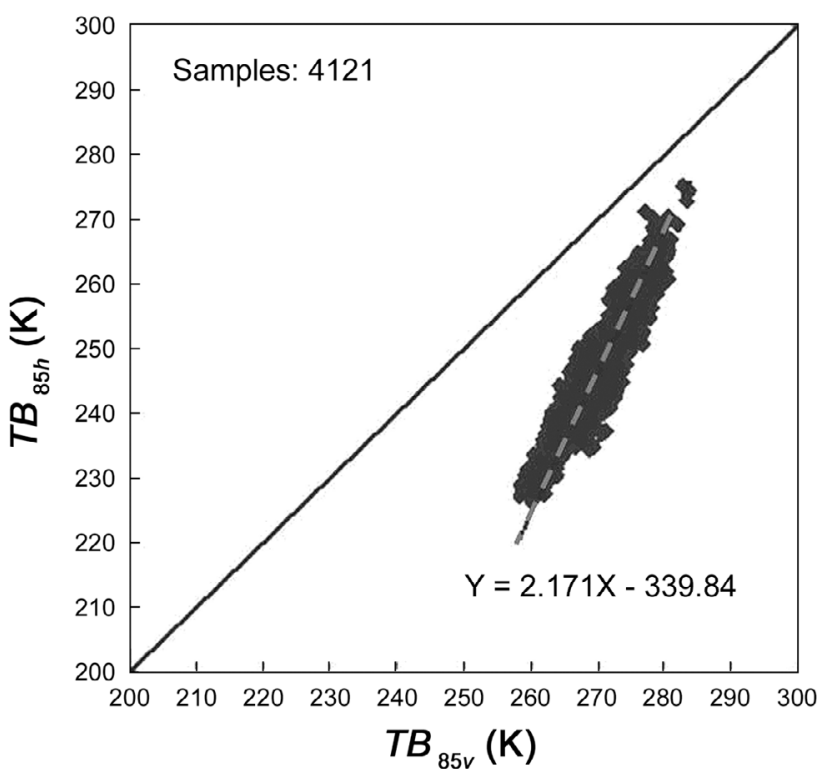

Fig. 4. The scatter diagram of TMI $T B_{85 v}$ and $T B_{85 h}$ data under cloudfree conditions of the atmosphere during the typhoon season in the sea areas adjacent to Taiwan. 


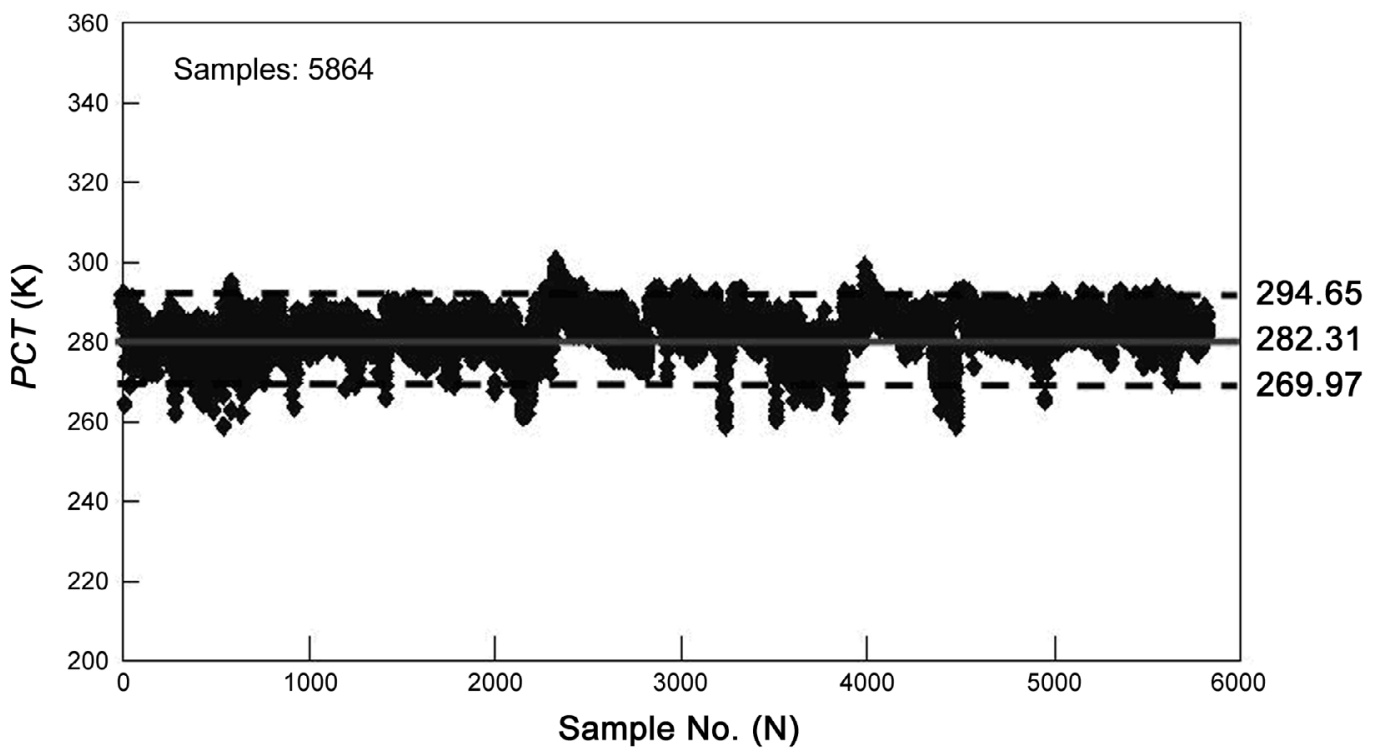

Fig. 5. The scatter diagram of the $P C T$ values with rain rates of $0 \mathrm{~mm} \mathrm{~h}^{-1}$ on land.

\subsection{Taiwan Land Rainfall Retrieval}

Using the TRMM/PR rain type data, the surface rainfall areas are divided into three categories, namely, convective rain areas, stratiform rain areas with bright band and stratiform rain areas without bright band. Individual rainfall retrieval is obtained using TRMM/TMI microwave data for each category to enhance the accuracy of rain rate estimation on land. Note that samples with the beam-filling error, near the swath edge in the TMI field of view are removed to avoid retrieval error.

\subsubsection{Rainfall Retrieval Equation for Convective Rain Areas}

In total, 164 pairs of effective sample data are used to derive the land rainfall retrieval formula for convective rain areas using linear regression. The scatter diagram of the $T i-P C T$ values and PR_RR for convective rain areas is shown in Fig. 6. The derivation of the coefficients of rainfall retrieval algorithm is based on the empirical method of Ferraro and Marks (1995), and the retrieval formula is as follows.

PCT_CON_RR $\left(\mathrm{mm} \mathrm{h}^{-1}\right)=0.368(T i-P C T)^{1.165}$

\subsubsection{Rainfall Retrieval Equation for Stratiform Rain Areas with Bright Band}

To obtain the rainfall retrieval for stratiform rain areas with bright band, data for 274 samples were used. The scatter diagram between the Ti-PCT values and the PR_RR is shown in Fig. 7. The retrieval formula is given as:
PCT_SBB_RR $\left(\mathrm{mm} \mathrm{h}^{-1}\right)=0.141(T i-P C T)^{1.140}$

Since the PCT method mainly uses the scattering character of the precipitation system to retrieve the surface rain rate, it is expected that the $P C T$ values for stratiform rain areas with bright band would be lower than those for convective rain areas under similar rainfall situation (rain rates) owing to the influence of the ice content above the bright band.

\subsubsection{Rainfall Retrieval for Stratiform Rain Areas with- out Bright Band}

From Fig. 8, it can be seen that 56\% (537/951) of the Ti-PCT values are negative for stratiform rain areas without bright band. Without bright band, it can be expected that shallow rain dominates and $P C T$ values will be higher as the ice content is low in the atmosphere. For samples with the $T i$-PCT values near $0 \mathrm{~K}$, the PR_RR ranges from 0.5 to $12 \mathrm{~mm} \mathrm{~h}^{-1}$. For larger Ti-PCT values, the relationship between $T i-P C T$ values and rain rates for this rain type is more or less like that for stratiform rain areas with bright band. This may be due to errors in identifying the existence of bright band. That is, although the bright band existed, it was not detected.

As most of the Ti-PCT values in this rain area are negative and there may be errors in detecting bright bands, the $P C T$ method is considered to be not suitable for retrieving the rain rate of this rain type. So, in this study, the rain rate retrieval is limited to convective rain areas and stratiform rain areas with bright band. 


\section{VALIDATION AND APPLICATION OF RAINFALL ESTIMATION IN TAIWAN}

\subsection{Validation}

Data from typhoons affecting Taiwan during 2007 - 2008, are used to validate the PCT method derived in Section 4 for the rainfall retrieval in Taiwan. The rainfall retrievals are verified with PR_RR. Other rain rate estimation products (SIL_RR and SIL_RR*) are also used to evaluate the performance of the $P C T$ method. SIL_RR is the rain rate estimated by the SIL method. SIL_RR* is the rain rate estimated by the SIL method with rainfall types classified.

The SIL method was developed by Chen et al. (2005) for Taiwan. The retrieval formulas are as follows.

$$
\begin{aligned}
S I L= & {\left[220.878-0.747 T B_{19 v}+0.554 T B_{21 v}\right.} \\
& \left.+0.00147 T B_{21 v}^{2}\right]-T B_{85 v}
\end{aligned}
$$

$\operatorname{SIL} \_R R\left(\mathrm{~mm} \mathrm{~h}^{-1}\right)=0.126 \operatorname{SIL} L^{1.239}$

SIL_RR* is the product of the method developed by Tsai et al. (2008). It includes SIL_CON_RR and SIL_SBB_ $\mathrm{RR}$, representing the estimated rain rates for convective rain areas and for stratiform rain areas with bright band, respectively. Their retrieval formulas are as follows:

SIL_CON_RR $\left(\mathrm{mm} \mathrm{h}^{-1}\right)=0.0120$ SIL $L^{1.918}$

$\operatorname{SIL} \_S B B \_R R\left(\mathrm{~mm} \mathrm{~h}^{-1}\right)=0.0052 S I L^{1.773}$

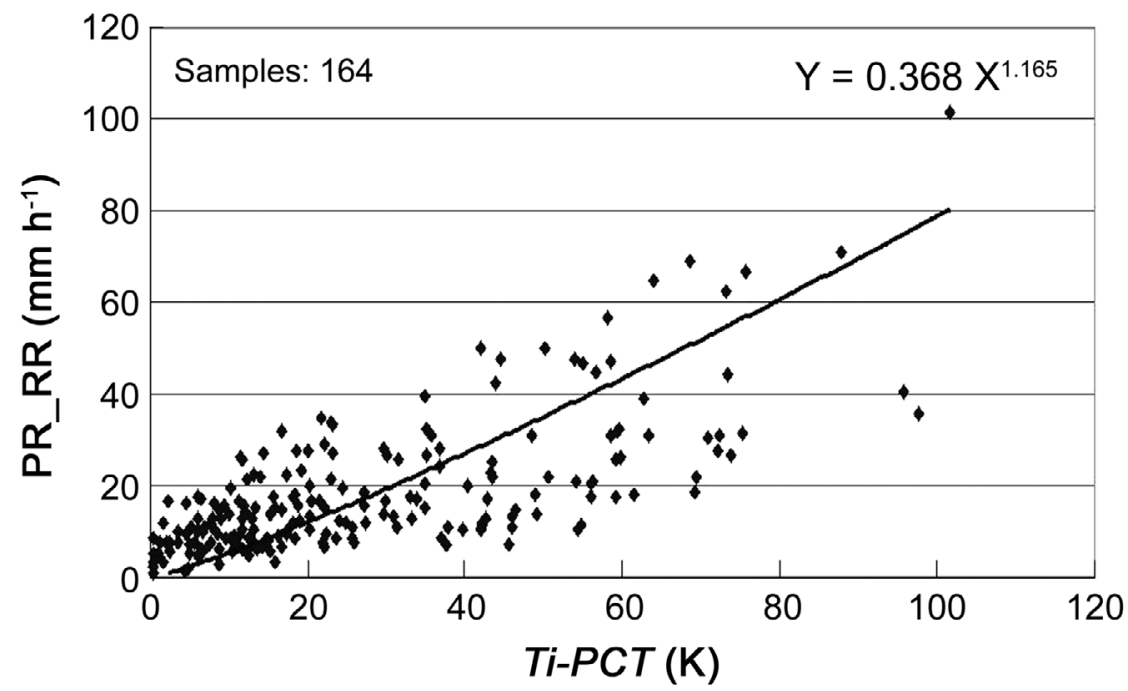

Fig. 6. Depiction of the relationship between the $(T i-P C T)$ formulated from the TRMM/TMI satellite data and the PR_RR for the convective rain areas.

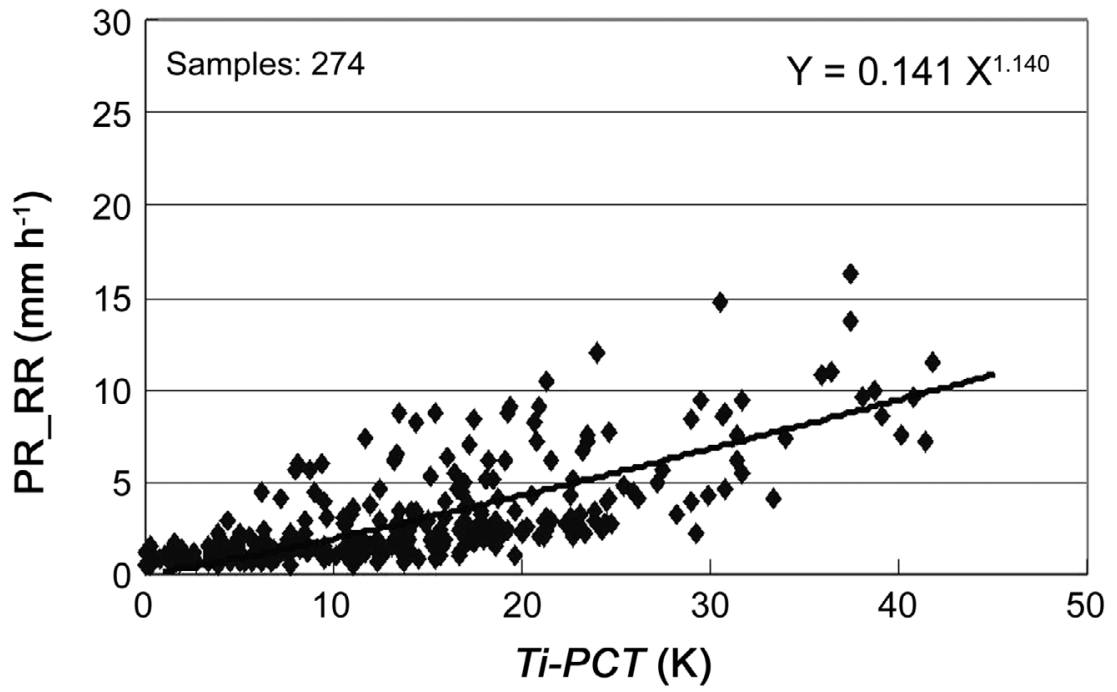

Fig. 7. As Fig. 6, but for the stratiform rain areas with bright band. 


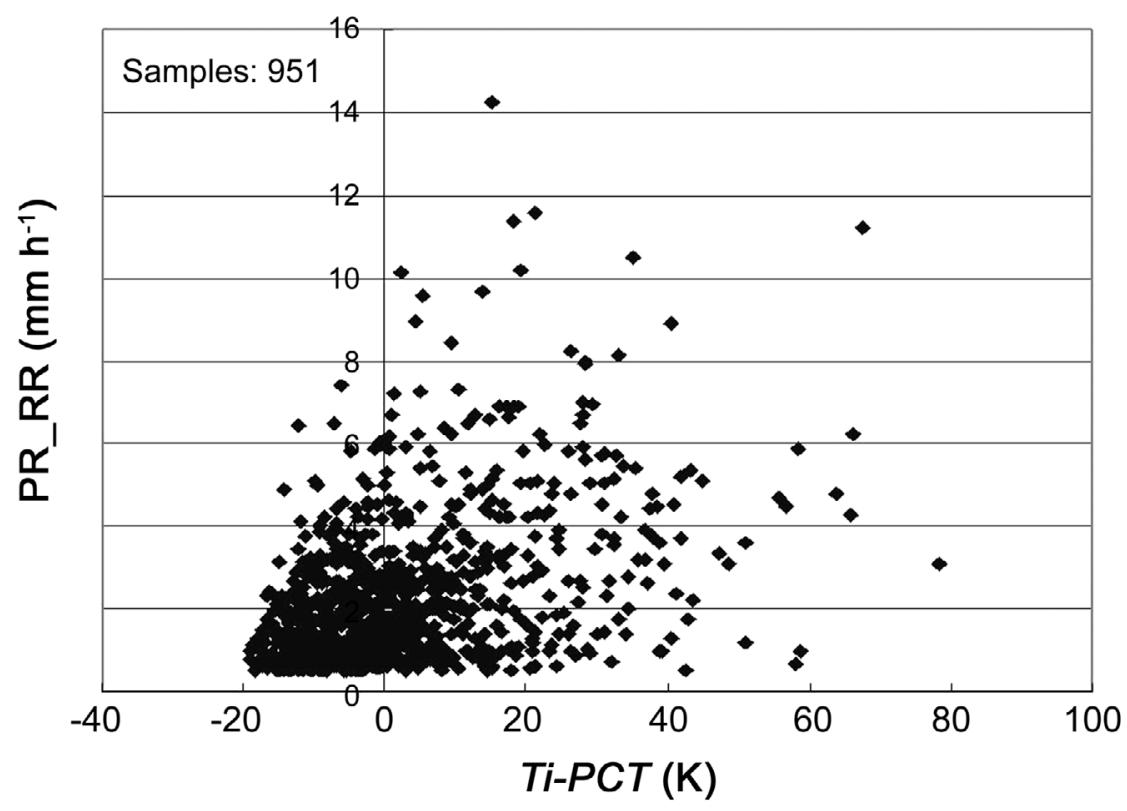

Fig. 8. As Fig. 6, but for the stratiform rainfall area without bright band.

To validate using PR_RR data, there are, 41 and 91 samples for the convective rain areas and the stratiform rain areas with bright band, respectively. The comparisons between the PR_RR and estimated rain rates with TMI microwave data are shown in Figs. 9 and 10. Some statistical analyses are shown in Table 2. It can be seen that SIL_RR, without rain-type classification, underestimates rain rates for 32 (approximately 80\%) samples of the convective rain areas and overestimates for all samples of the stratiform rain areas with bright band. On the other hand, considering raintype classification, for both SIL_RR* and PCT about 70\% samples of the convective rain areas are underestimated. For the stratiform rain areas with bright band, the retrieval has been improved when rain types are taken into account, though rain rates are still overestimated.

From the statistical analyses listed in Table 2, it can be seen that, compared with PR_RR, SIL_RR, SIL_CON_RR and PCT_CON_RR underestimate mean rain rates with mean differences of $-5.2,-3.7$ and $-3.4 \mathrm{~mm} \mathrm{~h}^{-1}$, respectively. PCT_CON_RR shows the closest value to the PR_RR in average. Based on these validation results, the $P C T$ method improves the accuracy of overall rain rate estimates for convective rain areas.

For stratiform rain areas with bright band, SIL_RR has the largest overestimation of $6.1 \mathrm{~mm} \mathrm{~h}^{-1}$. The rain rate retrievals by SIL_SBB_RR and PCT_SBB_RR are closer to PR_RR. Using different retrieval algorithms according to rain types determined from $P R$ rainfall products, differences of the mean rain rate are reduced from $6.1 \mathrm{~mm} \mathrm{~h}^{-1}$ (SIL_RR) down to $-0.34 \mathrm{~mm} \mathrm{~h}^{-1}$ (SIL_SBB_RR) and $0.04 \mathrm{~mm} \mathrm{~h}^{-1}$ (PCT_SBB_RR), and RMSE from $6.65 \mathrm{~mm} \mathrm{~h}^{-1}$ (SIL_RR) down to $1.73 \mathrm{~mm} \mathrm{~h}^{-1}$ (SIL_SBB_RR) and $1.68 \mathrm{~mm} \mathrm{~h}^{-1}$
(PCT_SBB_RR). These improvements are significant. From the above analyses, we concluded that the rain rate retrieval using TMI microwave data is improved when raintype classification is accounted for.

From the statistical analyses, we found that SIL_SBB_ RR and PCT_SBB_RR are closer to PR_RR, and the differences of the mean rain rate are -0.34 and $0.04 \mathrm{~mm} \mathrm{~h}^{-1}$, respectively. That indicates that SIL_SBB_RR performs better than PCT_SBB_RR. For convective rain areas, however, PCT_CON_RR performs better than SIL_CON_RR, with both smaller underestimation (0.77 times of PR_RR). In this study, the PCT method was developed with PR_RR data, while the SIL method was developed with rain gauge data by Tsai et al. (2008). We expect that the PCT method would perform better than the SIL method, when validated with PR RR data. In addition, the PCT method's resolution is $5 \mathrm{~km}$, other than $10 \mathrm{~km}$. This would further improve the accuracy for convective rainfall estimation.

To improve early warning forecasting, improvements in rainfall estimation for convective rain areas might be considered as the highest priority, as most rainfall in typhoons is from eyewall and rainband convection. Therefore, from the validation shown above, we expect that the PCT method with rain-type classification being taken into account could give more accurate quantitative rainfall estimation for typhoons as a whole.

\subsection{Application of the PCT Method}

In this section, the PCT method is applied to estimate rain rates in Taiwan during Typhoon Haitang (2005). The data were collected at 1017 UTC 19 July (Swath 1), 


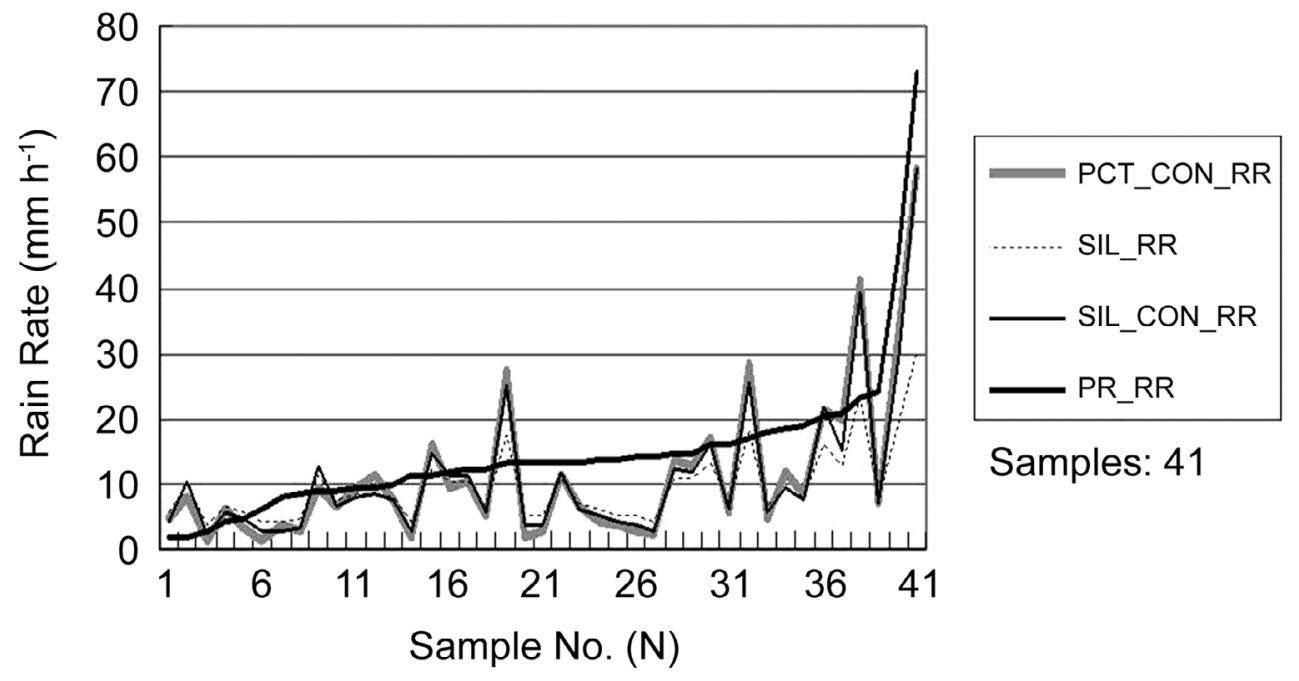

Fig. 9. The PR_RR (bold solid line), and the different results of rain rate retrievals, SIL_RR (dot line), SIL_CON_RR (solid line) and PCT_CON_ RR (bold gray line) of the 41 samples of convective rain areas. Samples are arranged according to the amount of PR_RR, from small to large.

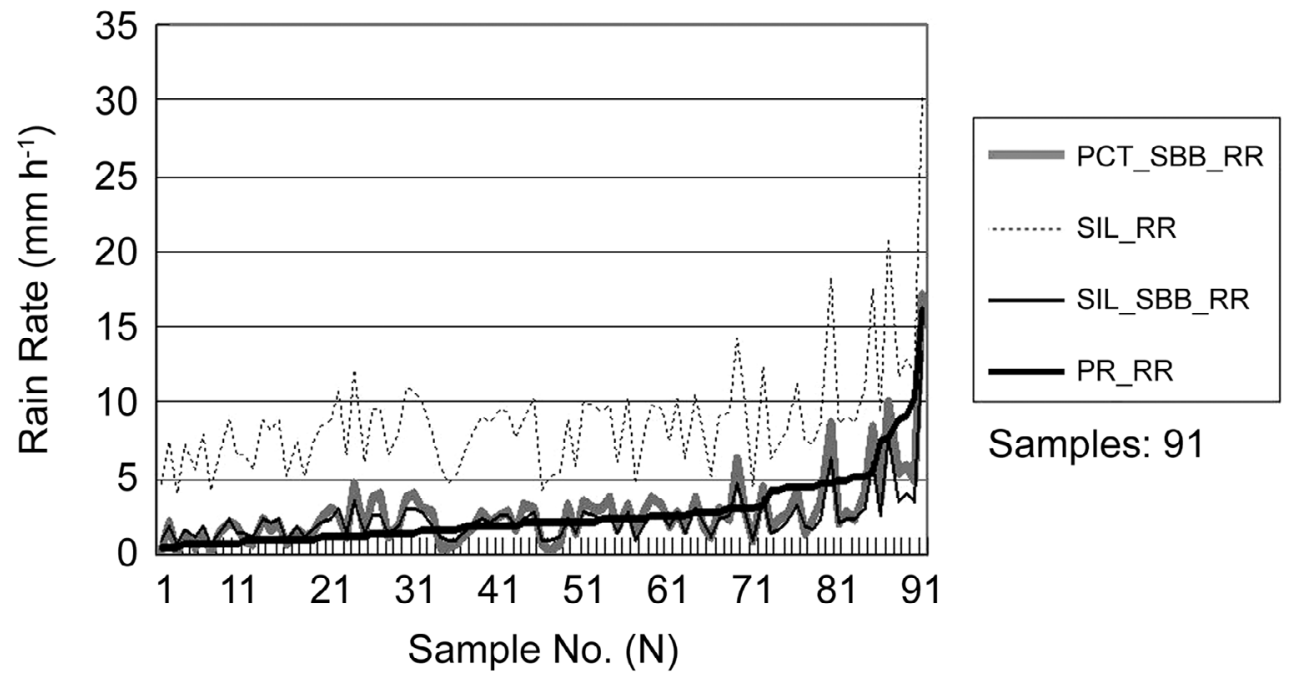

Fig. 10. The PR_RR (bold solid line), and the different results of rain rate retrievals, SIL_RR (dot line), SIL_SBB_RR (solid line) and PCT_SBB_ RR (bold gray line) of the 91 samples of stratiform rain areas with bright band. Samples are arranged according to the amount of PR_RR, from small to large.

Table 2. Statistical analyses of PR_RR and estimated rain rates for different rain areas associated with typhoons in $2007 \sim 2008$.

\begin{tabular}{|c|c|c|c|c|}
\hline \multirow{2}{*}{ Data type } & \multicolumn{2}{|c|}{ Convective rain areas } & \multicolumn{2}{|c|}{ Stratiform rain areas with bright band } \\
\hline & Mean rain rate $\left(\mathrm{mm} \mathrm{h}^{-1}\right)$ & RMSE $\left(\mathbf{m m ~ \mathbf { h } ^ { - 1 } )}\right.$ & Mean rain rate $\left(\mathrm{mm} \mathrm{h}^{-1}\right)$ & RMSE $\left(\mathbf{m m ~ h}^{-1}\right)$ \\
\hline PR_RR & 14.84 & - & 2.72 & - \\
\hline SIL_RR & 9.62 & 9.91 & 8.81 & 6.65 \\
\hline SIL_RR* & 11.15 & 8.12 & 2.38 & 1.73 \\
\hline PCT_RR & 11.40 & 8.23 & 2.76 & 1.68 \\
\hline
\end{tabular}


and 0249 UTC 20 July (Swath 2) 2005. The IR images of MTSAT and radar mosaic CV (composite of vertical maximum) images of reflectivity around Taiwan nearest in time for the two swathes are shown in Fig. 11. At 1000 UTC (1800 LST, Swath 1) 19 July 2005, the location of typhoon center was at $26.3^{\circ} \mathrm{N}, 119.7^{\circ} \mathrm{E}$. The rainfall on land of Taiwan was mainly associated with the convective outer rainband. At 0300 UTC (1100 LST) 20 July 2005, the typhoon had moved into mainland China. The rainfall on Taiwan was mainly associated with the following southwesterly flow. In the following, first, results for rain rate retrievals using the PCT method are demonstrated. Second, with PR_RR as the "best value," a comparison among the PCT and SIL methods (without and with rain-type classification) will be shown and discussed.

The observed and retrieved rain rate distributions for Swath 1 are shown in Fig. 12. From the comparison between the PR_RR rain rate distribution (Fig. 12a) and the PCT TB distribution (Fig. 12b), it can be seen that the patterns of the two are very similar to each other, especially in the heavy precipitation areas. The larger the PR rain rate in an area, the lower the PCT TB. Based on the PCT TB values, rainfall retrieval equations [see Eqs. (6) and (7)] are used according to rain types for the Taiwan land precipitation estimation. The results are shown in Fig. 12c. From the comparison between Figs. 12a and c, the rain rate pattern obtained by the PCT method is similar to the observed one, but with underestimated magnitude.

Figure 13 shows the distribution of $\mid$ SIL_RR - PR_RR |, |SIL_RR* - PR_RR |, and |PCT_RR - PR_RR | rainfall differences for Swath 1. The statistical analyses are shown in Table 3. For Swath 1, the sample number of the convective rain area (21) is comparable with that of the stratiform rain area (23). Rainfall differences are relatively large in convective rain areas, especially for SIL_RR*. On the other hand, the difference is small in stratiform rain areas. From Fig. 13a, it is shown that most of the absolute rainfall differences, |SIL_RR - PR_RR |, are about $10 \mathrm{~mm} \mathrm{~h}^{-1}$. In Fig. 13b, most of the rainfall differences, $\mid$ SIL_RR* - PR_RR $\mid$, are under $5 \mathrm{~mm} \mathrm{~h}^{-1}$, except in the convective rain areas, which has large values up to $40 \mathrm{~mm} \mathrm{~h}^{-1}$. Figure $13 \mathrm{c}$ shows a pattern of |PCT_RR - PR_RR | similar to Fig. 13b, but with (a)

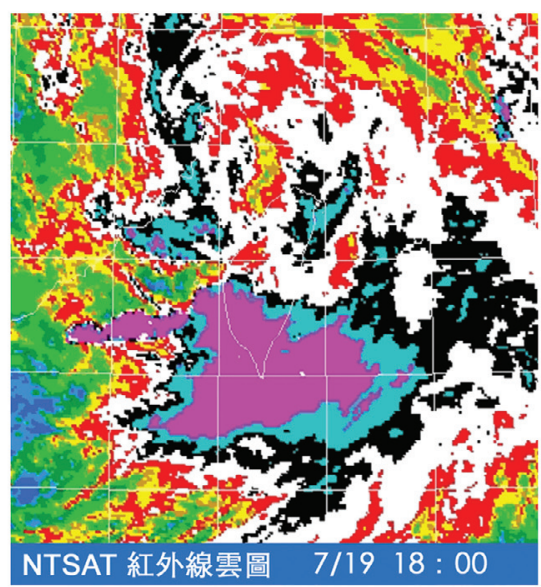

(c)

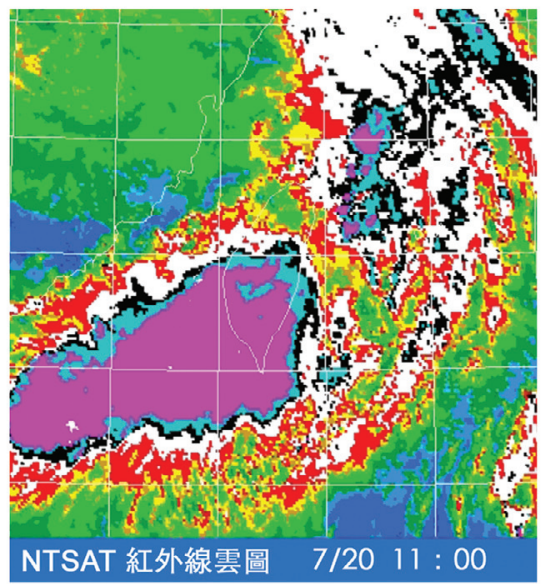

(b)

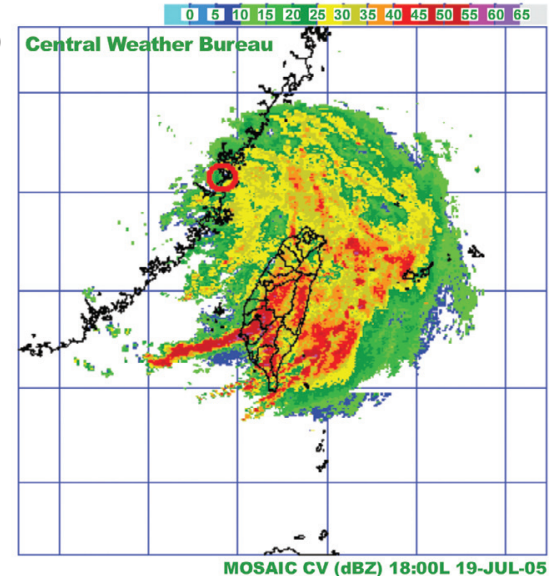

(d)

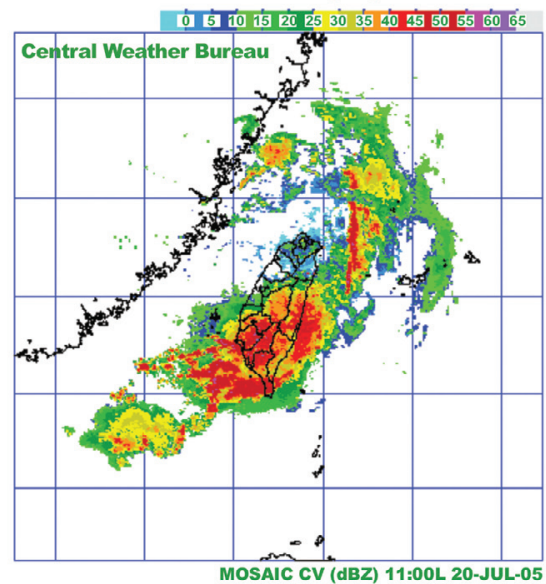

Fig. 11. (a) The IR image of MTSAT and (b) radar mosaic CV image of reflectivity (dBZ) around Taiwan at 1000 UTC (1800 LST, Swath 1 ) 19 July 2005 . The location of typhoon center $\left(26.3^{\circ} \mathrm{N}, 119.7^{\circ} \mathrm{E}\right)$ is shown by the red circles in (b). (c) and (d) are those for Swath 2 at $0300 \mathrm{UTC}(1100$ LST) 20 July 2005. 

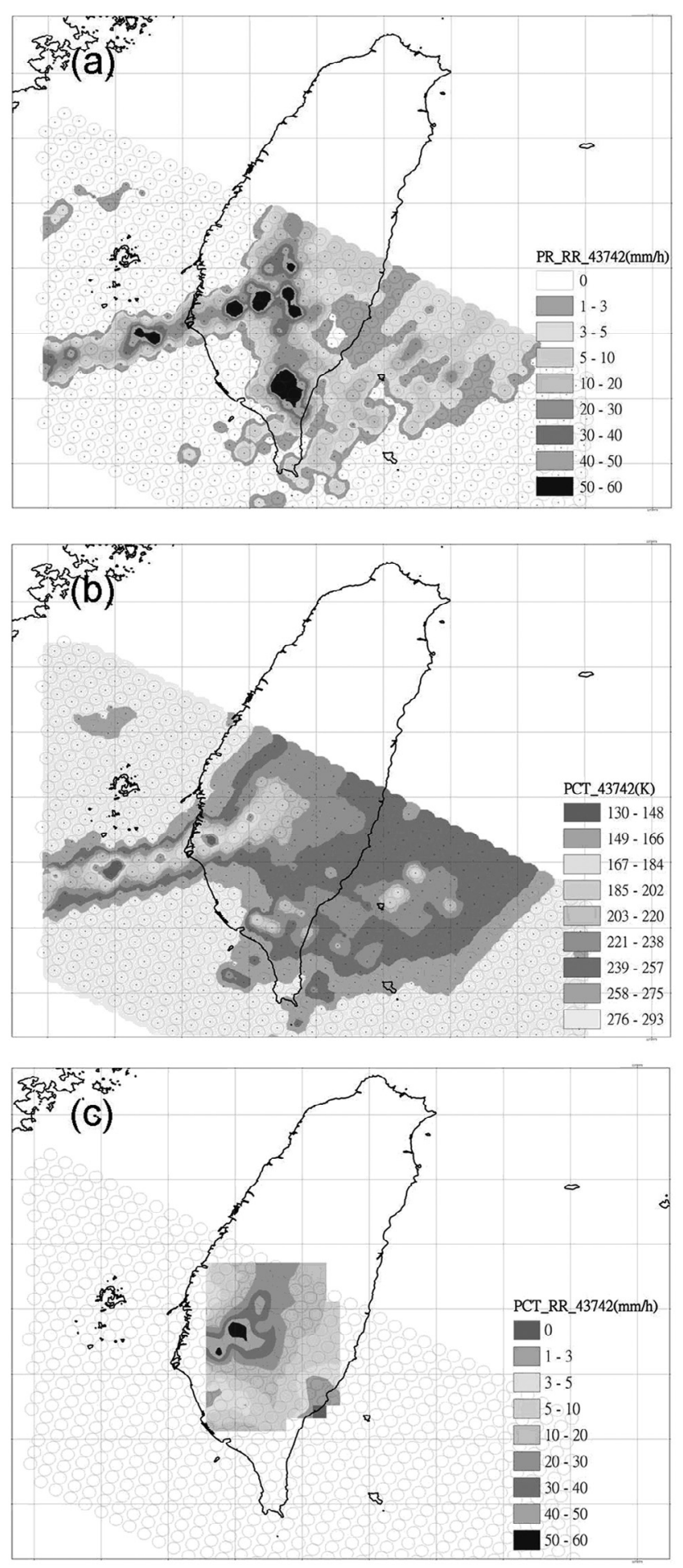

Fig. 12. (a) PR standard product of rain rates $\left(\mathrm{mm} \mathrm{h}^{-1}\right)$ at the level nearest to the surface; (b) The TB distribution of PCT (K); (c) PCT_RR $\left(\mathrm{mm} \mathrm{h}^{-1}\right)$ on land of Taiwan for Swath 1 at 1017 UTC (1817 LST) 19 July 2005.

significantly small rainfall differences in the convective rain areas.

From Table 3, it can be found that the absolute difference between the PCT_RR and PR_RR is the smallest,
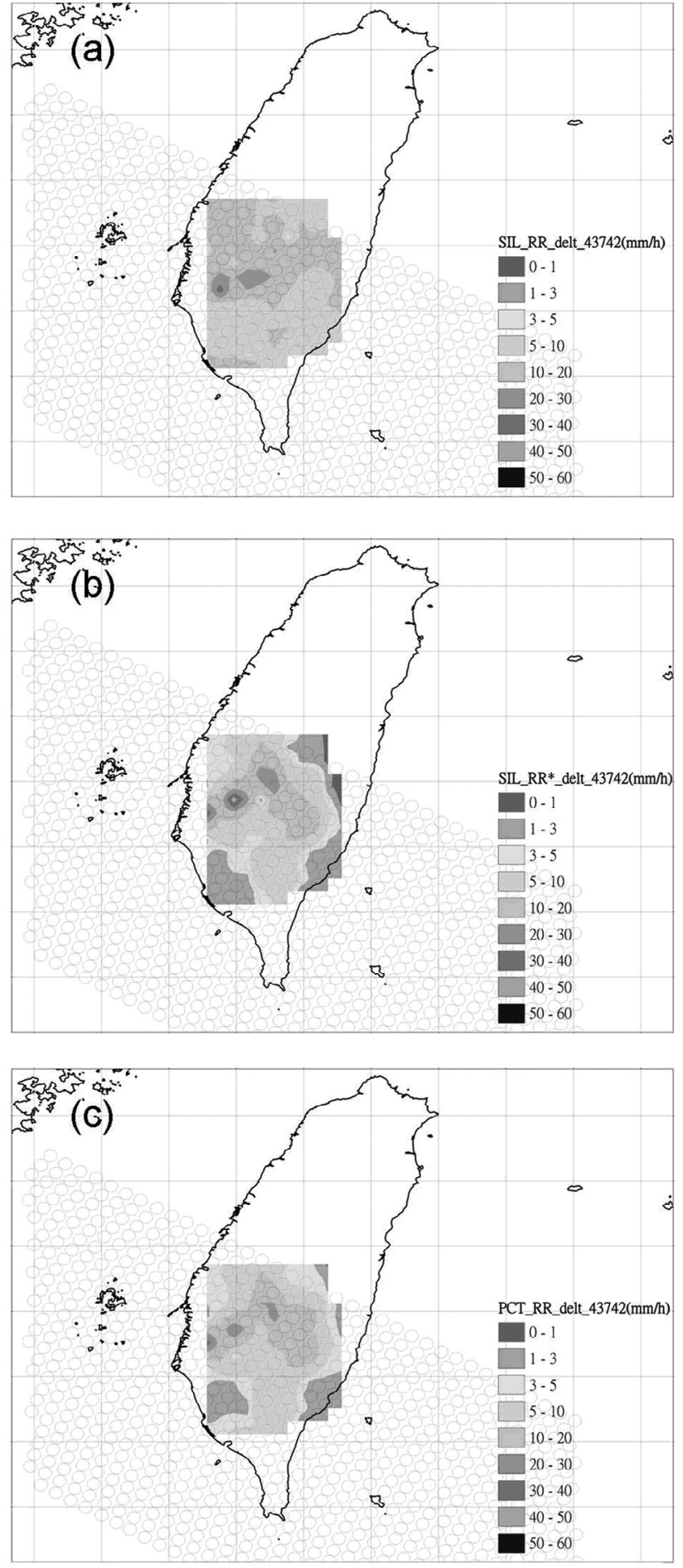

Fig. 13. The distribution of absolute differences between the TMI estimated rain rates and PR_RR for Swath 1: (a) $\mid$ SIL_RR - PR_RR |; (b) $\mid$ SIL_RR* - PR_RR |; (c) $\mid$ PCT_RR - PR_RR |.

and the correlation coefficient between them is the highest. SIL_RR* has the largest absolute difference among all the rain rate estimation methods due to large differences in convective rain areas. However, from the comparison of the 
Table 3. Comparison of PR_RR associated with Typhoon Haitang at 1017 UTC 19 July (Swath 1), and 0249 UTC 20 July (Swath 2) 2005. There are 44 and 53 samples for Swaths 1 and 2, respectively.

\begin{tabular}{lccccc}
\hline \multirow{2}{*}{$\begin{array}{l}\text { Rainfall } \\
\text { retrieval }\end{array}$} & \multicolumn{2}{c}{ Mean absolute difference } & & \multicolumn{2}{c}{ Correlation coefficient } \\
\cline { 2 - 3 } \cline { 5 - 6 } & Swath 1 & Swath 2 & & Swath 1 & Swath 2 \\
\hline SIL_RR & 11.9 & 8.1 & & 0.70 & 0.53 \\
SIL_RR* & 9.0 & 4.41 & & 0.77 & 0.72 \\
PCT_RR & 8.7 & 4.17 & & 0.81 & 0.71 \\
\hline
\end{tabular}

correlation coefficient, it is shown that SIL_RR* is better than SIL_RR as a whole. When rain type is not considered, SIL_RR has large differences compared to PR_RR regardless of rain types. Therefore, it shows the lowest correlation coefficients with PR_RR among all the three methods.

For $S$ wath 2, 53 samples are classified as stratiform rain areas. There are 2 samples of the convective rain area. From Figs. 14 and 15, the comparison among the three methods of rainfall retrieval is basically similar to that of Swath 1 . Most of the rainfall differences are about $10 \mathrm{~mm} \mathrm{~h}^{-1}$ for SIL_RR. For SIL_RR*, most of the rainfall differences are under $5 \mathrm{~mm} \mathrm{~h}^{-1}$, except in the convective rain area. Most of rainfall differences are smaller than $5 \mathrm{~mm} \mathrm{~h}^{-1}$ for PCT_RR, and the difference is smaller than that of SIL_RR* in the convective rain area. From Table 3, it is seen that by comparison with PR_RR, both the mean absolute differences of PCT_RR and SIL_RR* are less than $4.5 \mathrm{~mm} \mathrm{~h}^{-1}$. SIL_RR has a significant larger rainfall difference of $8.1 \mathrm{~mm} \mathrm{~h}^{-1}$. From the comparison of correlation coefficients, it is found that both PCT_RR and SIL_RR* are better than SIL_RR.

From the above analysis, the PCT method can improve the accuracy of the rainfall estimation over land for typhoon rainfall rate. Furthermore, with rain type classification, the SIL method can provide better rainfall estimated for stratiform rain areas, but not for convective rain areas.

\section{CONCLUSIONS}

Land rainfall retrieval using satellite microwave data mainly depends on the high-frequency scattering mechanism, and current studies on land rainfall retrieval are mostly based on the SIL method and the PCT method. In this study, we derived the $P C T$ equation and a new $\beta$ value of 0.461 is recommended for application to Taiwan during the typhoon season. Microwave data of TRMM/TMI and the $P C T$ method were used to establish the rainfall retrieval of typhoons on land of Taiwan. Data for cloud-free clear-sky conditions were used to set up the $P C T$ equation for Taiwan area. The rainfall threshold of $P C T$ was obtained using data with PR_RR of $0 \mathrm{~mm} \mathrm{~h}^{-1}$.
Without taking the rainfall types into consideration, the rain rate is often underestimated for convective rain areas and overestimated for stratiform rain areas. Thus, in this study, based on the data of TRMM/PR-2A25 standard products, the rain areas have been divided into three different rainfall types: convective, stratiform with bright band and without bright band. Using data from 26 typhoons affecting Taiwan during 2001 to 2006, the $P C T$ values are regressed with PR_RR on land, which then provides separate $P C T$ equations for the rain rates associated with different rainfall types on land of Taiwan. However, the relation between $\mathrm{Ti}$ $P C T$ values and land rainfall is not pronounced for the stratiform rain areas without bright band. As rainfall of this type is a warm-rain process which happens at altitudes below the freezing layer, radii of rain drops are small and the rain rate is low and so the improvement is not notable. These observations show that the characteristics of this rain type make the $P C T$ method unsuitable for the indirect rainfall retrieval using the high-frequency scattering mechanism.

To validate the $P C T$ method for rain rate retrieval in convective rain areas and stratiform rain areas with bright band, data associated with 10 typhoons affecting Taiwan from 2007 to 2008 were used. We found that using satellite microwave $T B$ s to estimate rain rates, it is necessary to consider the rain type classification. Otherwise, overestimation for stratiform rain areas is expected due to bright band and underestimation for convective rain areas. The validation results show notable improvement in rainfall retrieval for convective and stratiform rain areas, and PCT_CON_RR is better than SIL_CON_RR.

The PCT method is used to estimate rain rates in Taiwan during the landfall of Typhoon Haitang (2005). Rainfall retrievals associated with two swathes of TMI are examined against rain gauge observation. The PCT method is shown to provide more reasonable rainfall estimates compared with the SIL methods, with or without rain type classification. We conclude that the PCT method can improve the accuracy of the rainfall estimation on land for typhoons. Note that the PCT method uses $85-\mathrm{GHz}$ data with $5-\mathrm{km}$ pixel size finer than that of low-frequency channel data, it would have higher rainfall retrieval resolution than the SIL method. Overall, we recommend that the PCT method be used for quantitatively precipitation estimation. It should be noted that the PCT method, limited by the $5-\mathrm{km}$ resolution of TMI data, may underestimate the rain rates associated with convection, since it is common to see convection with horizontal scales smaller than $5 \mathrm{~km}$.

However, in this study, the TRMM/PR data are used to classify rain type. Because the swath of PR is only $215 \mathrm{~km}$ wide, not all data of TMI swath across the whole $760-\mathrm{km}$ width can be used to estimate rain rate. To enlarge the range of rain rate estimation, it is, therefore, necessary to establish a rain-type classification system for TRMM/TMI over Taiwan in the future. 

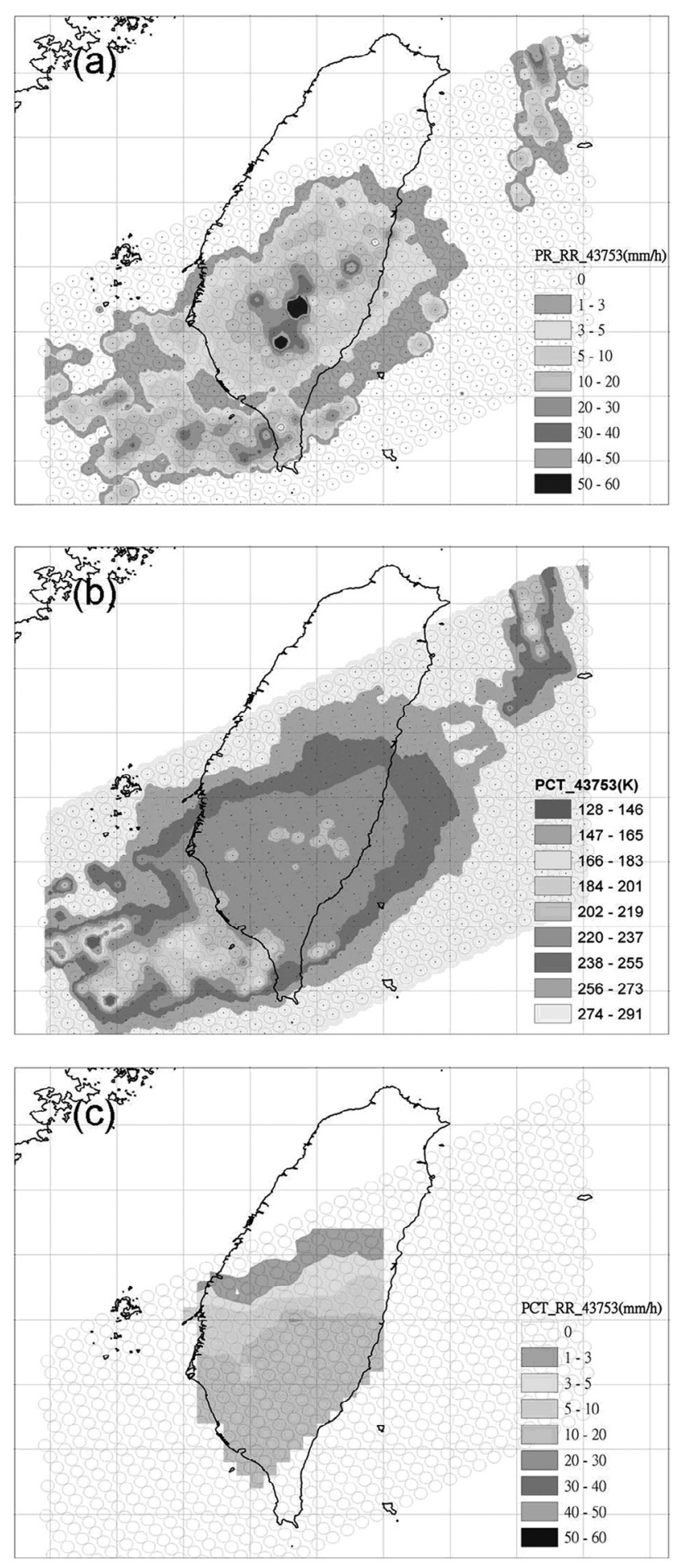

Fig. 14. (a) PR standard product of rain rates $\left(\mathrm{mm} \mathrm{h}^{-1}\right)$ at the level nearest to the surface; (b) The TB distribution of PCT (K); (c) PCT_RR $\left(\mathrm{mm} \mathrm{h}^{-1}\right)$ on land of Taiwan for Swath 2 at 0249 UTC (1049 LST) 20 July 2005.

Acknowledgements The authors would like to thank Dr. Ralph R. Ferraro at University of Maryland and an anonymous reviewer for their insightful comments that substantially improved the original manuscript, and the US Tropi-
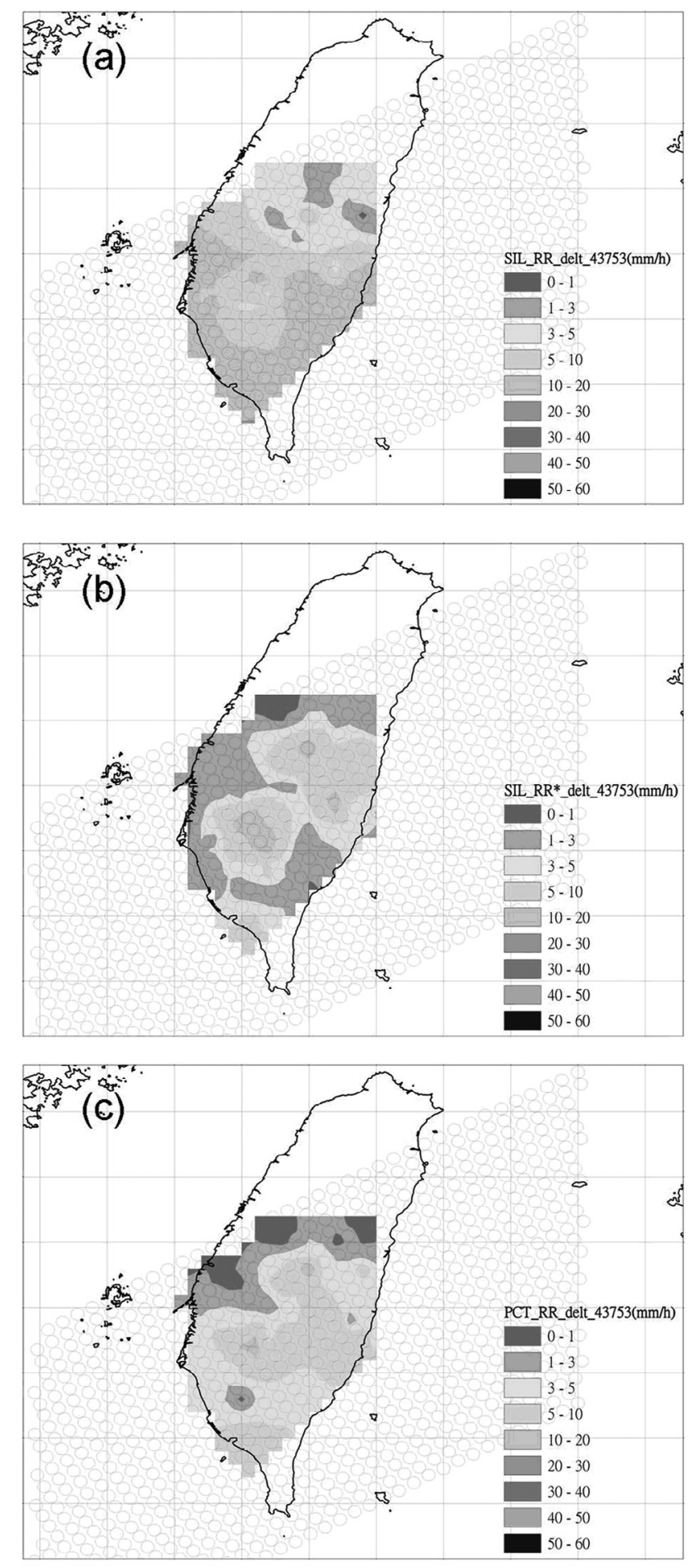

Fig. 15. The distribution of absolute differences between the TMI estimated rain rates and PR_RR for Swath 2: (a) $\mid$ SIL_RR - PR_RR |; (b) $\mid$ SIL_RR* - PR_RR |; (c) |PCT_RR - PR_RR |.

cal Rainfall Measuring Mission office for TMI, VIRS and PR data. Special thanks to Prof. Gin-Rong Liu's valuable suggestions and comments on this study. This research was funded by NSC 96-2625-Z-606-001. 


\section{REFERENCES}

Barrett, E. C. and C. Kidd, 1990: Rainfall monitoring by the SSM/I in the mid-latitudes. Fifth Conf. Satellite Meteorol. Oceanogr., London, England, Amer. Meteorol. Soc., 210-214.

Chen, W. J. and C. C. Li, 2000: Oceanic rain rate retrievals using TRMM Microwave Imager multi-channel brightness temperatures obtained during the 1998 SCSMEX. Terr. Atmos. Ocean. Sci., 11, 765-788.

Chen, W. J. and C. C. Li, 2002: Rain retrievals using Tropical Rainfall Measuring Mission and Geostationary Meteorological Satellite 5 data obtained during the SCSMEX. Int. J. Remote Sens., 23, 2425-2448, doi: 10.1080/01431160110075884. [Link]

Chen, W. J., M. D. Tsai, G. R. Liu, and M. H. Chang, 2005: The study of rainfall derived from the TRMM Microwave Imager data over Taiwan land - Using Scattering-Index method. Atmos. Sci., 33, 277-300. (in Chinese)

Chen, Y. C., 2004: Estimating typhoon quantitative precipitation by using AMSU Microwave data. Master Thesis, Chung Cheng Institute of Technology, National Defense University, Taoyuan, Taiwan, ROC. (in Chinese)

Demoss, J. D. and K. P. Bowman, 2007: Changes in TRMM rainfall due to the orbit boost estimated from buoy rain gauge data. J. Atmos. Ocean. Technol., 24, 1598-1607, doi: 10.1175/JTECH2082.1. [Link]

Ferraro, R. R. and G. F. Marks, 1995: The development of SSM/I rain-rate retrieval algorithms using ground based radar measurements. J. Atmos. Ocean. Technol., 12, 755-770, doi: 10.1175/1520-0426(1995)012<0755 :TDOSRR > 2.0.CO;2. [Link]

Ferraro, R. R., F. Weng, N. C. Grody, and A. Basist, 1996: An eight-year (1987-1994) time series of rainfall, clouds, water vapor, snow cover and sea ice derived from SSM/I measurement. Bull. Amer. Meteorol. Soc., 77, 891-905.

Fujita, T. T., 1986: Mesoscale classifications: Their history and their application to forecasting. In: Ray, P. S. (Ed.), Mesoscale Meteorology and Forecasting, American Meteorological Society, Boston, USA, 793 pp.

Grody, N. C., 1991: Classification of snow cover and precipitation using the Special Sensor Microwave Imager. J. Geophys. Res., 96, 7423-7435, doi: 10.1029/91JD00 045. [Link]

Holton, J. R., 2004: An Introduction to Dynamic Meteorology, 4th Ed., Elsevier Academic Press, New York, USA, $535 \mathrm{pp}$.

Hu, J. C., 2002: The study of estimating quantitative precipitation by using AMSU Microwave data over ocean. Master Thesis, Chung Cheng Institute of Technology, National Defense University, Taoyuan, Taiwan, ROC. (in Chinese)

Iguchi, T., T. Kozu, R. Meneghini, J. Awaka, and K. Okamoto, 2000: Rain-profiling algorithm for the TRMM precipitation radar. J. Appl. Meteorol., 39, 2038-2052, doi: 10.1175/1520-0450(2001)040<2038:RPAFTT $>2$. 0.CO;2. [Link]

Kidd, C., 1998: On rainfall retrieval using polarization-corrected temperatures. Int. J. Remote Sens., 19, 981-996, doi: 10.1080/014311698215829. [Link]

Kummerow, C., W. Barnes, T. Kozu, J. Shiue, and J. Simpson, 1998: The Tropical Rainfall Measuring Mission (TRMM) sensor package. J. Atmos. Ocean. Technol., 15, 809-817.

Prabhakara, C., R. Iacovazzi Jr., and J. M. Yoo, 2002: TRMM precipitation radar and Microwave Imager observations of convective and stratiform rain over land and their theoretical implications. J. Meteorol. Soc. Jpn., 80, 1183-1197.

Roberti, L. and C. Kummerow, 1999: Monte Carlo calculations of polarized microwave radiation emerging from cloud structures. J. Geophys. Res., 104, 2093-2104, doi: 10.1029/1998JD200038. [Link]

Spencer, R. W., 1986: A satellite passive 37-GHz scattering-based method for measuring oceanic rain rates. $J$. Appl. Meteorol., 25, 754-766, doi: 10.1175/1520-0450 (1986)025<0754:ASPGSB >2.0.CO;2. [Link]

Spencer, R. W., H. M., Goodman, and R. E., Hood, 1989: Precipitation retrieval over land and ocean with the SSM/I: Identification and characteristics of the scattering signal. J. Atmos. Ocean. Technol., 6, 254-273, doi: 10.1175/1520-0426(1989)006<0254:PROLAO>2.0.C O;2. [Link]

Todd, M. C. and J. O. Bailey, 1995: Estimates of rainfall over the United Kingdom and surrounding seas from the SSM/I using the polarization corrected temperature algorithm. J. Appl. Meteorol., 34, 1254-1265.

Tsai, M. D., W. J. Chen, C. H. Feng, G. R. Liu, and C. C. $\mathrm{Li}, 2006$ : Verification of TRMM/PR derived rain rate and its applications the study of precipitation over the Taiwan land. Atmos. Sci., 34, 1-24. (in Chinese)

Tsai, M. D., W. J. Chen, and J. L. Wang, 2008: Using rain type classification data for improving the accuracy of satellite rainfall estimation over land. Atmos. Sci., 36, 1-20. (in Chinese)

Weng, F., N. C. Grody, R. R. Ferraro, Q. Zhao, and C. T. Chen, 1997: Global cloud water distribution derived from special sensor microwave imager/sounder and its comparison with GCM simulation. Adv. Space Res., 19, 407-411, doi: 10.1016/S0273-1177(97)00048-3. [Link]

Wilheit, T., C. D. Kummerow, and R. Ferraro, 2003: Rainfall algorithms for AMSR-E. IEEE Trans. Geosci. Remote Sensing, 41, 204-214, doi: 10.1109/TGRS.2002.8 08312. [Link] 
William, S. O., Y. Hong, C. D. Kummerow, and J. Turk, 2001: A texture-polarization method for estimating convective-stratiform precipitation area coverage from passive microwave radiometer data. J. Appl. Meteorol., 40, 1577-1591, doi: 10.1175/1520-0450(2001)040<15
77:ATPMFE $>2.0 . \mathrm{CO} ; 2$. [Link]

Yang, M. J. and L. Ching, 2005: A modeling study of typhoon Toraji (2001): Physical parameterization sensitivity and topographic effect. Terr. Atmos. Ocean. Sci., 16, 177-213. 